\title{
Validity, Reliability and Convergent Analysis of Brazilian Version of Selection, Optimization and Compensation Questionnaire (QSOC)
}

\author{
Sionara Tamanini de Almeida ${ }^{1}$, Thais de Lima Resende ${ }^{2}$, Claus Dieter Stobäus ${ }^{3}$ \\ ${ }^{1}$ Geriatrics and Gerontologic Institute, Pontifical Catholic University of Rio Grande do Sul, Porto Alegre, Brazil \\ ${ }^{2}$ Faculty of Nursing, Nutrition and Physiotherapy Pontifical Catholic University of Rio Grande do Sul, Porto Alegre, Brazil \\ ${ }^{3}$ Postgraduate Program in Education and in Biomedical Gerontology, Pontifical Catholic University of Rio Grande do Sul, \\ Porto Alegre, Brazil \\ Email: stobaus@pucrs.br
}

How to cite this paper: de Almeida, S. T., de Lima Resende, T., \& Stobäus, C. D. (2016). Validity, Reliability and Convergent Analysis of Brazilian Version of Selection, Optimization and Compensation Questionnaire (QSOC). Creative Education, 7, 20742087.

http://dx.doi.org/10.4236/ce.2016.715207

Received: August 9, 2016

Accepted: September 9, 2016

Published: September 13, 2016

Copyright $\odot 2016$ by authors and Scientific Research Publishing Inc. This work is licensed under the Creative Commons Attribution International License (CC BY 4.0).

http://creativecommons.org/licenses/by/4.0/

\begin{abstract}
Population aging is a major challenge for global companies. The Selection, Optimization and Compensation Model proposed by the team of Baltes, is a way to explain ways to adapt to the difficulties of everyday life and the late stage of development deficits (aging). The study, which enables a $\mathrm{PhD}$ Thesis, is derived from discussions carried out during construction, and aims to demonstrate the validity of measures, reliability and convergent analysis of the Brazilian version of the instrument. It is conducted with 319 elderly aged 60 and 99 years old $(71.4 \pm 8.1)$, with a predominance of women $(70.8 \%)$, married $(40.1 \%)$ or widowed $(30.1 \%)$ using medications $(81.5 \%)$, with at least one health problem $(79.0 \%)$ and physically active (42.9\%). Even if the psychometric tests need to be worked out with continuity, with satisfactory levels of validity, internal consistency and convergent analysis, it demonstrates that the SOC model is potentially helpful to understand how the Brazilian elderly adapt to their problems of the day-a-day and processed successfully aging.
\end{abstract}

\section{Keywords}

Psichometrics, Validation Studies, Aging, Selection, Optimization, Compensation

\section{Introduction}

The aging population is a global phenomenon that refers to the change in the age structure of a population that produces an increase in the weight of persons above a certain age, considered as defining the onset of old age. The age that is considered an individual as old or belonging to old age varies from society to society, in the case of 
Brazil this lower limit is 60 years old (Carvalho \& Garcia, 2003). The growth of the elderly population is stated by the World Health Organization (WHO) when it indicates that between 2000 and 2050 the proportion of the world's population over 60 years old will double in about $11 \%$ to about $22 \%$ (WHO, 2016).

Aging is a major challenge for all societies since it carries a wealth of beliefs about the physical and biological declines, occurrence of diseases, problems, or losses. Of all the moments lived, the old age is the most incomplete, because of which is subject to many risks and negative results (Baltes \& Carstensen, 2000). When the individual is influenced mainly by losses in the biological domain, which extends to the various operating areas (social, psychological, economic, etc.) and the gains become smaller and smaller, it speaks of the incompleteness of human ontogeny (Baltes \& Smith, 2006).

When observed incompleteness in human ontogeny, the idea of a fuller life during old age is restricted. However, there are other aspects that may be considered and that somehow guarantee a growth potential and plasticity. The life-span perspective discusses the relationship gain/loss development/aging process. According to this view, development occurs in all stages of life and presents a joint expression of growth (gain) and decrease (loss). No phase of human development has only gains or losses and only this balance between these factors should be balanced through adaptive capabilities that the subject owns and develops (Baltes, 1987).

Thus, each individual has its own potential and different life goals and to achieve them, it is proposed to use three adaptation processes: selection, optimization and compensation. They constitute the Selection Model, Optimization and Compensation, or Model SOC of Baltes (Baltes \& Cartensen, 2000). The use of these three elements is considered as a tool for success in the aging process since they are mechanisms that help the individual toward achieving their personal goals (Néri \& Cachioni, 1999).

The SOC model is constituted by four strategies, namely the compensation strategy in which resources are used to maintain the desired operating level while some losses settle in the individual. This strategy aims to avoid negative results due to a decline/loss has occurred (Freund \& Baltes, 1998; Freund \& Baltes, 2002a; Li \& Freund, 2005). Compensatory resources include psychological processes and behavioral efforts to improve the functionality (Rabelo \& Néri, 2005).

In the optimization, which is a strategy used for the individual to acquire, improve and apply resources to achieve their goals, they can be: investment of time and energy to achieve a certain goal, acquisition and practice of new skills, persistence or have useful beliefs that help the individual to go ahead despite adversity. In short, the strategy consists of actions that seek to maximize earnings in a given area (Freund \& Baltes, 2002b). The psychological literature is replete with evidence of the optimization process: increased performance in certain areas has great interest and applicability in education, sports psychology and cognitive skills.

In Gerontology there are optimization examples in intervention studies, which highlights the possibility of growth even in older age (Baltes \& Cartensen, 2000).

Finally, the selection strategy, which does not use resources directly, refers to the property goals. The key expression to the strategy is the change of own goals. The li- 
mited availability of time and energy inherent in human existence requires the selection of targets, given that not all opportunities can be sought and/or achieved. Moreover, with the reduction of capacity and the increase in losses associated with older age, there is a decrease in activity in some areas, with the consequent concentration in specific fields (Baltes \& Silverberg, 1995; Freund \& Baltes, 1998; Freund \& Baltes, 2002b).

The selection is a necessary condition to achieve and maintain high levels of functioning, and fundamental part of the human development process as it delimits the path and direction. There are plenty of possibilities that the human being can develop, but at the same time, opportunities, biological, social and individual limitations particularize areas, and it selects actions (Li \& Freund, 2005).

Also regarding the selection, two types are distinguished: the loss-based selection and elective selection. The first refers to the reorganization of the person based life in some loss that has occurred and in this type there is a restructuring of the hierarchy of objectives, and the search for new targets or adaptation of new standards can be achieved by the person or from the environment around it. Elective selection is characterized by the choice of a particular purpose, in detriment of other not so important (Freund \& Baltes, 1998; Freund \& Baltes, 2002a, b; Bajor \& Baltes, 2003).

The model SOC (Baltes \& Cartensen, 2000) explains and gives opportunity to a different look on the losses through regulatory processes for human development, in order to assist in adapting to the difficulties and challenges of day-to-day, providing to the elderly a new way of looking at aging positively (Almeida et al., 2012).

It is determined from the use of an instrument, Selection, Optimization and Compensation Questionnaire-SOCQ (Baltes et al., 2005), which evaluates the adaptation of the difficulties facing individuals through the use of its strategies. Thus, the theoretical framework that supports the instrument is a life-span perspective-Development/Aging Psychology-when analyzed more broadly, and the SOC model is proposed by Baltes \& Baltes (1990), which implements the belief of a successful aging (Li \& Freund, 2005; Baltes, 1987). Therefore, the instrument is designed to measure the success/failure in aging and indicate the direction of care, from the inferences that can be realized in possession of the knowledge it provides.

From the observation that do not exist in Brazil instruments, by using the life coping strategies in the presented theoretical perspective, evaluating the adaptability of individuals facing difficulties, as well as having a clear recognition of the need for an instrument that could assist the understanding of what makes successful aging in the Brazilian socio-cultural context, we developed this study. It aimed to perform validity tests, convergent reliability and analysis of SOCQ instrument which had been translated into Portuguese of Brazil, i.e. the Selection Questionnaire, Optimization and Compensation (QSOC) (Almeida, Resende, \& Stobäus, 2013).

\section{Method}

This study is reflective product and discussion among authors, and fragment of a Doctoral Thesis, which will culminate in the evaluation of the Portuguese version of Brazil's 
Selection, Optimization and Compensation Questionnaire to older people developed in Geriatrics and Gerontology Institute Pontifical Catholic University of Rio Grande do Sul (IGG-PUCRS).

\subsection{Participants}

The sample for QSOC validation consisted of 319 elderly living in Porto Alegre, they do activities at the following places; in the Geriatric Clinic of the Hospital São Lucas (Coral Totality of PUCRS; History Course of the PUCRS, Art, Leisure and elderly physical activity Center-Celari/UFRGS, in Porto Alegre, Gymnastics Society-Sogipa in Gym Tesourinha, from Municipal Secretary of Sports of Porto Alegre, in the Club of the Association of Friends of the Brazil-AABB Bank, the Yacht Club Union-GNU, the Porto Alegrense Assistance to Needy Company-SPAAN, the Leopoldina Youth Club in Stilo Academy, the Mothers Club of St. Francis of Assisi Church, and the Association of Gauchos Athletic Veterans-Avega. The elderly were recruited in these different places according to the criteria of availability and accessibility (Maguirre \& Rogers, 1989), all aged over 60 years. They were excluded from the sample older you had a cognitive deficit evidenced by the previous application of the mini-mental state examination or who had hearing impairment that prevented them to understand the researchers who carried out the data collection, and seniors who presented inability to speak.

\subsection{Sample Size}

The criterion for the sample size was based on a practical recommendation given by Pasquali (1999) and Dassa (1999) suggest that include a minimum of 5 subjects for each item of the instrument. However, due to missing data were collected from over 79 elderly, totaling the sample in 319 elderly (Dassa, 1999; Pasquali, 1999).

\subsection{Instruments}

Besides QSOC, which is presented in more detail below, in the study five other instruments were used: 1) Questionnaire Bio-socio-demographic 2) Mini-Mental State Examination 3) WHOQOL-BREF (quality life), 4) the IPAQ-short version (physical activity) and 5) the resilience scale (Bertolucci \& Brucki, 1994; Fleck et al., 2000; Benedetti, Mazo, \& Barros, 2004; Wagnild \& Young, 1993; Pesce, Assis, \& Avanci, 2005; Baltes et al., 2005).

Bio-socio-demographic questionnaire Simple was developed for the study, it records information professionals, social and health of the elderly.

The score of the Mini Mental State Examination was used as a criterion for exclusion of subjects. It is an overall evaluation of the cognitive functioning, composed of an objective assessment of orientation, memory, calculation and language. The maximum score is 30 points, and the minimum score for cognitive impairment identification is less than 18 points for a school of 1 to 8 years incomplete and less than 26 points for education equal to 8 years or more (Bertolucci, Brucki, et al., 1994). Thus, subjects who achieved a score lower than that considered normal by the test were excluded. 
The WHOQOL-BREF is a specific instrument for measuring the quality of life, composed from Whoqol-100, longer. It contains 26 questions in different domains: physical, psychological, social relationships, environment and general area. The instrument features a Likert scale, ranging from 1 (nothing) and 5 points (completely). The total score of the subject is the perceived quality of life level (Fleck et al., 2000; Bertolucci, Bruck, Campacci, \& Juliano, 1994). The idea of using the WHOQOL-BREF in the study was to compare their content with that obtained in QSOC in order to verify a possible association between the constructs of the instruments.

The short version of IPAQ allows estimating the weekly time spent on physical activities of moderate to vigorous and in different areas of life: work, housework, transportation and leisure (Benedetti, Mazo, \& Barros, 2004). So let us classify individuals into 4 categories: sedentary, irregularly active (type B and type A), active or very active. The function of the instrument in this study was to identify the level of physical activity of the elderly, to characterize the sample.

It was also used the Resilience Scale developed by Wagnild \& Young (in Pesce, Assis, \& Avanci, 2005), which consists of 25 items with amplitude between 25 and 175 points, with higher values indicating high resilience (Wagnild \& Young, 1993; Pesce, Assis, \& Avanci, 2005). The function of the use of the instrument in the study was to compare the resilience construct with the construct contained in QSOC, to adapt to the problems of day-to-day, that is, make a convergent analysis of the constructs.

\subsection{Procedures and Analytical Approach}

The procedures used to validate the QSOC conform to commonly accepted principles in the literature (Baltes, Staudinger, \& Lindenberger, 1999; Fleck, Louzada, Xavier, Chacamovich et al., 2000; Pasquali, 1999). After contact and formal consent of Prof. Lindenberger, current director of the Max Planck Institute for Human Development, an institute that generated QSOC the five methodological stages of translation and cultural adaptation of the instrument were performed: initial translation, synthesis of translations, back translation, analysis by a committee of experts, and pretest with 34 seniors, analyzing the understanding of each sentence of the instrument and its application (Almeida, Resende, \& Stobäus, 2013).

\subsection{Ethical Aspects}

To collect Thesis data it was carried out the assessment and subsequent approval of the Scientific Committee of the Institute of Geriatrics and Gerontology at PUCRS, being submitted and approved by the Research Ethics Committee of PUCRS (no. 10/05258). It was requested from each participant signing two Consent way and Informed (IC), leaving a copy with them and another with Almeida researcher.

\subsection{Data Analysis}

The data were originally stored in Excel $2007^{\circledR}$ program and then were analyzed using the Statistical Package for Social Sciences software (SPSS $\odot$ ) version 17.0. For the cha- 
racterization of the sample was used descriptive statistics (measures of central tendency, dispersion, frequency distribution).

The internal consistency of each instrument strategies and overall were assessed using Cronbach's alpha coefficient.

The QSOC instrument translated and adapted for the Brazilian population and is composed of 48 dichotomous items. Baltes et al. (2005), when carried out the validation of the original instrument, chose to form portions with four items randomly. In this study also grouped the 48 items in 12 installments. For each strategy consists of 12 items was performed an exploratory factor analysis with the estimation method Maximum Likelihood without rotation and fixing a priori on three factors for each instrument approach, with a value for the adequacy test of Kaiser-Meyer-Olkin greater than 0.50 .

Thus, for each strategy were adjusted three installments, with the criterion the factor loadings more correlated or so that all items within the same portion presented positive correlation.

Each strategy contains three installments (12 items) was subjected to a confirmatory factor analysis of the type called convergent validity, according to the design of Spider; \& Zambaldi (2008).

Pearson's correlations were performed between the plots for each of the four components of QSOC and calculated the internal consistency by Cronbach's alpha coefficient as well.

Convergent analysis was analyzed by Pearson correlation between the total scores of each strategy and the scores of two instruments already validated and widely used in Brazil, resilience scale (Pesce, Assis, \& Avanci et al. 2005), and a questionnaire on quality of life (Fleck, 2005).

\section{Results}

The characterization of the sample is shown in Table 1, the results show that the average age was $71.4 \pm 8.1$ years old, with a predominance of women $(70.8 \% ; n=226)$, with education above high school (incomplete/Graduation $=23.5 \%$; high school degree $=$ $21.9 \%)$, who live in a marital status $(40.1 \%)$ or are widows $(30.1 \%)$. The use of medication on a regular basis was observed in $81.5 \%(n=260)$ of the investigated. As for health problems, $79.0 \%(\mathrm{n}=251)$ reported having some health problem while $21.0 \%(\mathrm{n}=$ 67) reported no health problems.

A high portion of the sample, $76.2 \%(\mathrm{n}=243)$, said they were engaged in some leisure activity. About IPAQ classification, $42.9 \%(\mathrm{n}=137)$ were considered active and $16.3 \%(n=52)$ as very active, and $6.6 \%(n=21)$ were characterized as sedentary.

\subsection{Reliability}

Considering the four strategies for QSOC (ES, SBP, O and C), the analysis of internal consistency by Cronbach's alpha coefficient for each strategy was calculated.

The coefficient was calculated for each ES strategies $(\alpha=0.518)$, SBP $(\alpha=0.746)$, O 
Table 1. Absolute and relative distribution for sex, education, marital status, medicine, leisure activity and classification IPAQ; mean and standard deviation for the age of the total sample. Porto Alegre, POA, 2013.

\begin{tabular}{|c|c|}
\hline Variables & Total $\%(n=319)$ \\
\hline \multicolumn{2}{|l|}{ Sex } \\
\hline Male & $93(29.2)$ \\
\hline Female & $226(70.8)$ \\
\hline \multicolumn{2}{|l|}{ Age } \\
\hline Rate $\pm \mathrm{P}$ deviation & $71.4 \pm 8.1$ \\
\hline \multicolumn{2}{|l|}{ Study years } \\
\hline Semi illiterate & $6(1.9)$ \\
\hline Incomplete primary & $25(7.8)$ \\
\hline Complete primary & $29(9.1)$ \\
\hline Incomplete elementary school & $23(7.2)$ \\
\hline Complete elementary school & $39(12.2)$ \\
\hline Incomplete high school & $14(4.4)$ \\
\hline Complete high school & $70(21.9)$ \\
\hline Incomplete/complete high school & $75(23.5)$ \\
\hline Post-graduation & $38(11.9)$ \\
\hline \multicolumn{2}{|l|}{ Marital Status } \\
\hline Single & $44(13.8)$ \\
\hline Married/living as a married person & $128(40.1)$ \\
\hline Apart/divorced & $51(16.0)$ \\
\hline Widow(er) & $96(30.1)$ \\
\hline \multicolumn{2}{|l|}{ Medicine Users } \\
\hline Regular & $260(81.5)$ \\
\hline Irregular & $10(3.1)$ \\
\hline Do not use any medicine & $49(15.4)$ \\
\hline \multicolumn{2}{|l|}{ Health Problem Scope } \\
\hline With health problem & $251(79.0)$ \\
\hline Any health problem & $67(21.0)$ \\
\hline \multicolumn{2}{|l|}{ Leisure Activity } \\
\hline Yes & $243(76.2)$ \\
\hline No & $76(23.8)$ \\
\hline \multicolumn{2}{|l|}{ Rating IPAQ } \\
\hline Active & $137(42.9)$ \\
\hline Very active & $52(16.3)$ \\
\hline Active irregularly A & $65(20.4)$ \\
\hline Active irregularly B & $44(13.8)$ \\
\hline Sedentary & $21(6.6)$ \\
\hline
\end{tabular}

Exploratory Factor Analysis. Based on exploratory factor analysis were organized three intrinsic installments each QSOC strategy. 
( $\alpha=0.795)$, C $(\alpha=0.632)$. Only the coefficient of elective selection has exceeded the thresholds suggested in the literature, minimum $\alpha=0.600$ for Cronbach (1996) and Churchill Jr. (1999), so we believe that the instrument was valid and proposing to effectively measure what proposes consistently, i.e. the population which was applied the instrument did not affect representatively consistency of its items.

\subsection{Convergent Analysis}

The correlations regarding the scale scores of resilience and WHOQOL-BREF, with the total score of each strategy and the overall total score of the items correlated with statistical significance were the elective selection and optimization strategies with the total score of the instrument. The highest correlation and more considered appropriate value was the total score of the optimization strategy, i.e., $r>0.300$.

Considering the data on quality of life, the indices of the physical, psychological and general WHOQOL-BREF were statistically significant with the total scores of all the SOC strategies, as well as the overall total score of the instrument. The correlation of the social dimension was statistically significant with the optimization and compensation strategy, as well as the overall score of QSOC. The environmental dimension was not statistically only when correlated with the total score of the SE strategy.

However, the correlations were not considered, according to the literature, as strong, for the most part been with $r$ values $<0.300$. Only the psychological dimension and the total score of the WHOQOL-BREF in the total score of the optimization strategy that values were slightly above $r=0.300$.

\subsection{Confirmatory Factor Analysis}

The version of the questionnaire with the parcels proposed does not confirm the original study construct, according to the analysis carried out according to the authors mentioned above. The result, in the software application, displays the following warning:

\section{Warnings}

The number of degrees of freedom (0) is not positive. Factor analysis may not be appropriate.

Correlations among themselves the plots of each strategy are presented in Table 2 below.

\section{Discussion}

\subsection{Exploratory Factor Analysis}

Baltes et al. (2005) in their study of the original instrument validation issued three plots for each QSOC strategies. Each plot consisted of the sum of the four items. The same was done in this study. Exploratory analysis of Taylor, Bagby, \& Parker (2003) revealed a three-factor solution, each factor reflecting the expected processes, that is, each expected strategy. The plots showed correlations to moderate with values mostly above 0.60. In the Brazilian instrument, these correlations showed with diverse values, i.e. the SE strategy correlations were weak to moderate (values between 0.198 and 0.299), 
Table 2. Correlations between the plots of each strategy.

\begin{tabular}{cccc}
\hline & \multicolumn{3}{c}{ Correlations } \\
\hline Parts & P1_SE & P2_SE & P3_SE \\
P1_SE & --- & $0.299^{* *}$ & $0.298^{* *}$ \\
P2_SE & $0.299^{* *}$ & --- & $0.198^{* *}$ \\
P3_SE & $0.298^{* *}$ & $0.198^{* *}$ & --- \\
& P1_SBP & P2_SBP & P3_SBP \\
P1_SE & --- & $0.428^{* *}$ & $0.594^{* *}$ \\
P2_SE & $0.428^{* *}$ & --- & $0.458^{* *}$ \\
P3_SBP & $0.594^{* *}$ & $0.458^{* *}$ & --- \\
& P1_O & P2_O & P3_O \\
P1_O & --- & $0.682^{* *}$ & $0.507^{* *}$ \\
P2_O & $0.682^{* *}$ & --- & $0.495^{* *}$ \\
P3_O & $0.507^{* *}$ & $0.495^{* *}$ & --- \\
& P1_C & P2_C & P3_C \\
P1_C & --- & $0.245^{* *}$ & $0.500^{* *}$ \\
P2_C & $0.245^{* *}$ & --- & $0.401^{* *}$ \\
P3_C & $0.500^{* *}$ & $0.410^{* *}$ & --- \\
\hline
\end{tabular}

${ }^{* *}$ the correlation was meaningful at level of $1 \%$.

in the SBP strategy moderate to strong (values between 0.428 and 0.594 ), on the strategy (values between 0495 and 0.682), moderate to strong, and compensation strategy between weak and moderate (values between 0.245 and 0.500) (Picon, 2006).

\subsection{Internal Consistency}

The SOCQ presented an alpha coefficient of Cronbach good for both the total sample and as to each of the dimensions, with values considered high for Cronbach (1996). Garson (2005), and Pestana \& Gageiro (2003), Nunnally (1978) and Taylor et al. (2003), recommend that the adequacy and satisfactoriness Alpha model is tested by using the criteria: Alpha indices above 0.80 are considered desirable; indices above 0.70 are considered recommended; rates above 0.60 should be accepted only for use in research, or inadvisable clinical use.

The internal consistency of the original instrument in different dimensions (meaning strategies) was with values between 0.68 and 0.78 , considered recommended.

In the Brazilian instrument values were lower. The lowest value was the elective selection strategy (0.518) and the higher the optimization strategy (0.795). However, for three QSOC strategies recommended values were considered, according to the literature, demonstrating that these strategies have precision in their measurements. This is consistent dimensions and evaluating reliably what it claims to assess.

\subsection{Confirmatory Factor Analysis}

The Brazilian study did not confirm the theoretical construct, it is a scale with dichoto- 
mous items and was validated in another reality and it was not with the elderly participants.

\subsection{Convergent Analysis}

This study collected data from two instruments validated in Brazil, the resilience scale and WHOQOL-BREF, to make the convergent analysis of QSOC.

The construct resilience was elected to perform association with QSOC depending on which is a similar concept, which refers to the ability of human beings to overcome the effects of adversity they face, and even out strengthened from this situation (Melillo, Ojeda, \& Rodriguez, 2004), with the action to adapt to facing a difficulty considered a risk and the possibility of building new ways of life and a subjective process from the face of stressful and/or traumatic situations (Vanistendael 1999; Lindstrom, 2001). As Baltes et al. (2005) suggest that each QSOC process contributes to the adaptive expertise, individuals who report using display QSOC presumably higher levels of resilience.

The resilience scale developed by Wagnild and Young in 1993 is an instrument used to measure the degree of the individual resilience. It consists of 25 items with Likert type response, ranging from 1 (strongly disagree) to 7 (strongly agree). The scale scores have a range between 25 - 175 points, with higher values indicating high resilience. The scale was adapted for use with Brazil in 2005, by Pesce, Assis, Avanci et al. (2005).

The result was that there was overlap of the total SOC of SE strategy of SE and O and the overall total score of SOC compared to the resilience instrument, but the correlations were not high enough to characterize the strong convergent validity between the instruments. One explanation for the result may be found in the absence of scale validation studies of resilience in older adults. The study, translation and cultural adaptation and psychometric analysis used sample of public school students of São Gonçalo, aged between 12 and 19 years (Pesce et al., 2005). Resilience, despite being a concept that can be understood as clearly associated with aging, there is not enough research to demonstrate their association, therefore, is not known for sure if the scale is suitable for the application in the elderly.

According to Souza \& Cerveny (2006), it was from 1999 emerged issues related to resilience in older adults and adults facing the death of family members. There is a way to go until it reaches the most concrete hypotheses. However, even in the face of incompleteness, the study of resilience is configured in the health promotion field (Travis, 2002).

Limitations and uncertainties exist with respect to Resilience Scale and this is another important point that can support the explanation that the QSOC not presented as clear results of association with this scale in convergent analysis. Only with the dissemination of knowledge on the subject and with the accession of new researchers may reach a more stable and replicable Resilience Scale, contributing not only to the methodological development, but mainly for knowledge, dissemination and promotion of the necessary resources to that people overcome difficulties experienced lifelong (Pesce, Assis, Avanci et al., 2005). 
The instrument's original version tested the convergent validity with various validated instruments with similar constructs such as: Ryff inventory of psychological well-being, which provided strong evidence that the SOC is associated with higher levels of positive emotions and good design, for a multifaceted inventory-being. Tenflex questionnaire, which includes two scales that assess assimilative and accommodative trends, which showed that there was significant overlap to QSOC, which checks activity versus state orientation after a failure or during an action revealed significant association the QSOC (Baltes et al., 2005).

The scale that assesses personality variables presented as a result of not associated with QSOC; intellectual functioning operationalized as verbal skills and cognitive style obtained satisfactory associations with QSOC and other scale that evaluates thinking styles with sharp general positive associations of hierarchical style of thinking with all QSOC facets and specific associations component, involving elective selection and a monarchical style of thinking (Baltes et al., 2005).

The concept of quality of life was also associated with QSOC in the Brazilian version. This concept, which guides the instrument used is recommended by the group of quality of life of the World Health Organization (WHO, 2016) defines the term as the individual's perception of their position in life in the context of culture and value system in which they live and in relation to their goals, expectations, standards and concerns (The WHOQOL Group, 1994).

Thus, the quality of life is subjective, multidimensional and includes positive and negative elements of evaluation. The instrument itself, which was used, the WHOQOL$\mathrm{BREF}$, is specific to the measurement of quality of life, taken from a longer period instrument, the WHOQOL-100 (Fleck et al., 2000).

It contains 26 questions, two general questions and the remaining 24 represent each of the 24 facets that make up the original instrument. Unlike the WHOQOL-100, where each of the 24 facets is evaluated from 4 questions, the WHOQOL-BREF is evaluated by only a matter because it is composed of domains (physical, psychological, social, environmental and general area). In Brazil, the Portuguese version was validated according to the methodology recommended for the version of the instrument, with the psychometric characteristics fulfilling the required performance criteria (Fleck, Louzada; Xavier, Chachamovich et al., 2000).

Subjective quality of life assessments can be seen as a reflection of an important facet of adaptive expertise (Baltes et al., 2005). The well-being and quality of life reflect the outcome of the subject answer that was able to strike a balance that can be viewed through the physical, psychological, social, environmental and general area. The expectation is that the behaviors associated with SOCQ show a positive association with each of the quality of life dimensions. The results were similar to those found in the implementation of Resilience Scale, they were not high enough to characterize the strong convergent validity, although there was an overlap of items.

Here is some difficulty in carrying out this psychometric analysis, depending on the model SOC, according to the authors, Baltes et al. (2005) consider that QSOC is a dif- 
ferentiated and conceptually unique instrument without equivalent. Given the results of convergent analysis, it is necessary to make other associations with other instruments and the result may be the same or different to that found with the resilience scale and WHOQOL-BREF.

\section{Conclusions}

Although it has been used strong methodological rigor in the analyses presented here, these are the first steps of verifying the evaluation results of the Brazilian instrument. It is recommended to check the applicability of the questionnaire in several Brazilian cities and in public diversified elderly on the heterogeneity of the aging process with a higher concentration of subjects with the same characteristics, that is, both in terms of education, socioeconomic level, specificity in certain type of disease as a profession, marital status.

The process of determining the validity of a scale or measuring instrument is continuous and may extend for years with final validation achieved after several studies using different methodological approaches. It is also recommended that other scholars are engaged in analysis of existing measuring instruments for the improvement of QSOC and subsequent psychometric comparisons.

It is noteworthy that there are advantages in using self-report scales, such as QSOC, mainly for its ease of application and low cost does not require prior exhaustive training application. However, perhaps an abbreviated Brazilian version is advantageous possibility for easier filling and lower demand application time.

\section{References}

Almeida, S. T., Resende, T. L., \& Stobäus, C. D. (2013). Adaptação Transcultural do Selection, Optimization and Compensation Questionnaire (SOC), para aplicação a idosos [Selection of Transcultural Adaptation, Optimization and Compensation Questionnaire (SOC), for Application to the Elderly]. Revista Brasileira de Geriatria e Gerontologia, 16.

http://dx.doi.org/10.1590/S1809-98232013000200003

Almeida, S. et al. (2012). Perspectiva life span na Psicologia do envelhecimento: um olhar diferenciado sobre perdas na velhice [Perspective Life Span in Aging Psychology: A Different Look on Losses in Old Age]. In: C. H. A. Schwanke et al. (Org.)., Atualizações em Geriatria e Gerontologia IV. Aspectos demográficos, biopsicossociais e clínicos do envelhecimento (pp. 97-122). Porto Alegre: EdiPUCRS.

Bajor, J., \& Baltes, B. (2003). The Relationship between Selection Optimization with Compensation, Conscientiousness, Motivation, and Performance. Journal of Vocation Behavior, 63, 347367. http://dx.doi.org/10.1016/S0001-8791(02)00035-0

Baltes, M., \& Carstensen, L. (2000). The Process of Successful Aging. In: E. Markson, \& L. Hollis (Eds.), Intersections of Aging-Readings in Social Gerontology (pp. 65-81). Los Angeles: Roxbury Publishing Company.

Baltes, P. et al. (2005). A Psychological Model to Age Successfully: Selective Optimization with Compensation. USA: Max Planck Institute for Human Development: Germany; University of Virginia. http://www.margret-baltes-stiftung.de/PBB-Website/Baltes_Rio_Gerontology.pdf

Baltes, P. (1987). Theoretical Propositions of Life-Span Developmental Psychology: On the Dynamics between Growth and Decline. Developmental Psychology, 23, 611-626. 
http://dx.doi.org/10.1037/0012-1649.23.5.611

Baltes, P., \& Baltes, M. (1990). Psychological Perspectives on Successful Aging: The Model of Selective Optimization with Compensation. In: P. Baltes, \& M. Baltes (Eds.), Successful Aging: Perspectives from the Behavioral Sciences (pp. 1-34.). New York: Cambridge University Press. http://dx.doi.org/10.1017/CBO9780511665684

Baltes, P., \& Silverberg, S. (1995). A dinâmica dependência-autonomia no curso de vida [The Dependency-Autonomy Dynamic in the Course of Life]. In A. Néri (Org.), Psicologia do envelhecimento (pp. 73-110). São Paulo: Papirus.

Baltes, P., \& Smith, J. (2006). Novas fronteiras para o futuro do Envelhecimento: da velhice bem sucedida do idoso jovem aos dilemas da quarta Idade [New Frontiers for the Future of Aging: The Successful Aging of the Young Old to the Dilemmas of the Fourth Age]. A terceira idade, 17, 7-31.

Baltes, P., Staudinger, U., \& Lindenberger, U. (1999). Lifespan Psychology: Theory and Application to Intellectual Functioning. Annual Reviews Psychology, 50, 471-507.

http://dx.doi.org/10.1146/annurev.psych.50.1.471

Benedetti, T., Mazo, G., \& Barros, M. (2004). Aplicação do Questionário Internacional de Atividades Físicas para avaliação do nível de atividades físicas de mulheres idosas: validade concorrente e reprodutibilidade teste-reteste [International Survey of Application of Physical Activities to Assess the Level of Physical Activity of Older Women: Concurrent Validity and Test-Retest Reproducibility]. Revista Brasileira de Ciência \& Movimento, 12, 25-34.

Bertolucci, P. H. F., Brucki, S. M. D., Campacci, S., \& Juliano, Y. (1994). Mini Exame do Estado Mental e Escolaridade [Mini Mental State Examination and Education]. Arquivos de Neuropsiquiatria, 52, 1-7. http://dx.doi.org/10.1590/S0004-282X1994000100001

Carvalho, J., \& Garcia, R. (2003). O envelhecimento da população brasileira: um enfoque demográfico [The Aging of the Population: A Demographic Approach]. Cadernos de Saúde Pública, 19, 726-733. http://dx.doi.org/10.1590/S0102-311X2003000300005

Cronbach, L. J. (1996). Fundamentos da Testagem Psicológica [Foundations of Psychological Testing]. Porto Alegre: Artes Médicas.

Dassa, A. C. (1999). Analyse multidimensionnelle exploratoire et confirmative [Exploratory and Confirmatory Multidimensional Analysis]. Montreal: Univesité de Montreal.

Fleck, M. P., Louzada, S., Xavier, M., Chachamovich, E., Vieira, G., Santos, L. et al. (2000). Application of the Portuguese Version of the Abbreviated Instrument of Quality of Life Whoqol-Bref. Revista de Saúde Pública, 34, 178-183. http://dx.doi.org/10.1590/S0034-89102000000200012

Freund, A., \& Baltes, P. (1998). Selection, Optimization, and Compensation as Strategies of Life Management: Correlations with Subjective Indicators of Successful Aging. Psychology and Aging, 13, 531-543. http://dx.doi.org/10.1037/0882-7974.13.4.531

Freund, A., \& Baltes, P. (2002a). Life-Management Strategies of Selection, Optimization, and Compensation: Measurement by Self-Report and Construct Validity. Journal of Personality and Social Psychology, 82, 642-662. http://dx.doi.org/10.1037/0022-3514.82.4.642

Freund, A., \& Baltes, P. (2002b). The Adaptiveness of Selection, Optimization, and Compensation as Strategies of Life Management: Evidence from a Preference Study on Proverbs. Journal of Gerontology Psychology Science, 57B, 426-434. http://dx.doi.org/10.1093/geronb/57.5.P426

Garson, D. (2005). PA 765 Statnote: An Online Textbook. http://www2.chass.ncsu.edu/garson/pa765/statnote.htm

Li, S., \& Freund, A. (2005). Advances in Lifespan Psychology: A Focus on Biocultural and Personal Influences. Researches in Human Development, 2, 1-23. 
http://dx.doi.org/10.1080/15427609.2005.9683342

Lindstrom, B. (2001). O significado de resiliência [The Meaning of Resilience]. Revista Adolescencia Latinoamericana, 112, 133-137.

Maguirre, T., \& Rogers, T. (1989). Proposed Solutions for Non Randomnes in Educational Research. Canadian Journal of Education, 14, 170-181. http://dx.doi.org/10.2307/1495349

Melillo, A., Suárez-Ojeda, E. N., \& Rodríguez, D. (2004). Resiliencia y subjetividad. Los ciclos de la vida [Resilience and Subjettivity. Life Cycles]. Buenos Aires: Paidós.

Néri, A., \& Cachioni, M. (1999). Velhice bem-sucedida e educação [Successful Aging and Education]. In A. Néri, \& G. Debert (Org.), Velhice e Sociedade [Aging and Society] (pp. 113-139). Campinas-SP: Papirus.

Nunnally, J. C. (1978). Psychometric Theory(2nd ed.). New York: McGraw-Hill.

Pasquali, L. (1999). Instrumentos psicológicos: manual prático de elaboração [Psychological Instruments: Practical Manual Preparation]. Brasília: IBAPP.

Pesce, R., Assis, S. G., Avanci, J. Q., Santos, N. C., Malaquias, J. V., \& Carvalhaes, R. (2005). Adaptação transcultural, confiabilidade e validade da escala de resiliência [Cross-Cultural Adaptation, Reliability and Validity of the Resilience Scale]. Cadernos de Saúde Pública, 21, 436-448. http://dx.doi.org/10.1590/S0102-311X2005000200010

Pestana, M. H., \& Gageiro, J. G. (2003). Análise de dados para ciências sociais: A complementaridade de SPSS [Data Analysis for Social Sciences: The Complementarity of SPSS] (3rd ed.). Lisboa: Edições Silabo.

Rabelo, D., \& Neri, A. (2005). Recursos psicológicos e ajustamento pessoal frente à incapacidade funcional na velhice [Psychological Resources and Personal Adjustment Front of Disability in Old Age]. Psicologia em Estudo, 10, 403-412. http://dx.doi.org/10.1590/S1413-73722005000300008

Souza, M. T. S., \& Cerveny, C. M. O. (2006). Resiliência Psicológica: Revisão da literatura e análise da produção científica [Psychological Resilience: Literature Review and Analysis of Scientific Production]. Revista Interamericana de Psicologia, 40, 119-126.

Taylor, G. J., Bagby, R. M., \& Parker, J. P. A. (2003). The Twenty-Item Toronto Alexithymia Scale IV. Reliability and Factorial Validity in Different Languages and Cultures. Journal of Psychosomatic Research, 55, 277-283. http://dx.doi.org/10.1016/S0022-3999(02)00601-3

The WHOQOL Group (1994). The Development of the World Health Organization Quality of Life Assessment Instrument (The WHOQOL). In: J. Orley, \& W. Kuyken (Eds.), Quality of Life Assessment: International Perspectives (pp. 41-60). Heidelberg: Springer Verlag.

Travis, J., \& Wail, M. (2002). Reflections on the Crime Decline: Lesson for the Future? In J. Travis, \& M. Wail, Proceedings from the Urban Institute Crime Decline Forum (pp. 1-49). Washington DC: Urban Institute Justice Policy Center.

Vanistendael, S. (1999). Prévenir le trauma d'une agression sexuelle: Un éclairage à partir de la résilience [Prevent the Trauma of Sexual Assault: A Light from the Resilience]. In: M. P. Poilpot (Ed.), Souffrir et se construire (pp. 107-123). Ramonville: Éditions Érès.

Wagnild, G., \& Young, H. (1993). Development and Psychometric Evaluation of Resilience Scale. Journal of Nursing Measurement, 1, 165-178.

World Health Organization (WHO) (2016). Ageing. http://www.wpro.who.int/topics/ageing/en/ 
Submit or recommend next manuscript to SCIRP and we will provide best service for you:

Accepting pre-submission inquiries through Email, Facebook, LinkedIn, Twitter, etc. A wide selection of journals (inclusive of 9 subjects, more than 200 journals)

Providing 24-hour high-quality service

User-friendly online submission system

Fair and swift peer-review system

Efficient typesetting and proofreading procedure

Display of the result of downloads and visits, as well as the number of cited articles

Maximum dissemination of your research work

Submit your manuscript at: http://papersubmission.scirp.org/ 